\title{
\begin{tabular}{l|l} 
Mitraries & DSpace@MIT
\end{tabular}
}

\author{
MIT Open Access Articles
}

\section{Fabrication of the First US ITER TF Conductor Sample for Qualification in SULTAN Facility}

The MIT Faculty has made this article openly available. Please share how this access benefits you. Your story matters.

Citation: Gung, C.-y. et al. “Fabrication of the First US ITER TF Conductor Sample for Qualification in SULTAN Facility." Applied Superconductivity, IEEE Transactions on 19.3 (2009): 1474-1477. (C) 2009 IEEE

As Published: http://dx.doi.org/10.1109/tasc.2009.2018203

Publisher: Institute of Electrical and Electronics Engineers

Persistent URL: http://hdl.handle.net/1721.1/52417

Version: Final published version: final published article, as it appeared in a journal, conference proceedings, or other formally published context

Terms of Use: Article is made available in accordance with the publisher's policy and may be subject to US copyright law. Please refer to the publisher's site for terms of use. 


\title{
Fabrication of the First US ITER TF Conductor Sample for Qualification in SULTAN Facility
}

\author{
Chen-yu Gung, Nicolai N. Martovetsky, Daniel R. Hatfield, John R. Miller, Ji-Hyun Kim, and Joel H. Schultz
}

\begin{abstract}
A pair of $3.5 \mathrm{~m}$ long ITER TF size straight conductors has been fabricated into a conductor short sample and submitted to the SULTAN facility at CRPP for cold test. The sample used a triplet-based cabling pattern in one leg and a septuplet-based in the other. The legs had different cabling pattern and strand diameters, but the same void fraction. To assure the accuracy in measurement of the conductor current sharing temperature, it is important to have uniform current distribution in the cable, which requires uniformly low interstrand resistivity in the joint. In the present sample, the cable/subcable wraps and the chrome plating on all strands were removed from the cable in the termination, followed by compacting and heat treating the termination in a Glidcop sleeve. To improve current transfer, the sintered termination was further filled with soft solder before it was soldered to the copper profile. To clarify the effectiveness of short sample instrumentation, the sample was equipped with enhanced number of sensors and with sensor mounts penetrating the conductor jacket for the thermometers and voltage taps positioned in the high field zone. This paper presents the experiences in sample fabrication and instrumentation, and outlines the parameters used in the key processes.
\end{abstract}

Index Terms-Superconducting cables, superconducting magnets, thermonuclear fusion.

\section{INTRODUCTION}

A NUMBER of $3.5 \mathrm{~m}$ long straight ITER TF conductor samples, some with different fabrication processes of the $\mathrm{Nb} 3 \mathrm{Sn}$ strands, have been recently fabricated by different ITER Domestic Agents (DAs) and tested in SULTAN to evaluate the effects of cabling pitch and conductor void fraction on the Tcs, Ic, and degradation by cyclic load [1]-[3]. The test results showed that the differentiation in the Tcs was not consistently correlated with the design of the strand and the featured modification in the cable construction [2]. In a few conductors, the measured results were significantly affected by the transverse voltage component.

The first US TF conductor sample TFUS1 fabricated for test in SULTAN was designed in late 2006, which consisted of a baseline and an alternate conductor legs. The sample design window as well as the baseline conductor leg using a tripletbased cabling pattern followed the ITER specification for the TF conductor sample [4]. The alternate leg designed by the USDA

Manuscript received August 26, 2008. First published June 23, 2009; current version published July 15, 2009. This work was supported by the US ITER Office.

C. Gung, J.-H. Kim and J. H. Schultz are with the MIT Plasma Science and Fusion Center, Cambridge, MA 02139, USA (e-mail: gung@psfc.mit.edu).

N. N. Martovetsky, D. R. Hatfield, and J. R. Miller are with the US ITER Office, Oak Ridge, TN 37380, USA (e-mail: martovetskyn@ornl.gov).

Color versions of one or more of the figures in this paper are available online at http://ieeexplore.iee.org.

Digital Object Identifier 10.1109/TASC.2009.2018203
TABLE I

CONDUCTOR SPECIFICATION

\begin{tabular}{|c|c|c|}
\hline & Baseline & Alternate \\
\hline \multicolumn{3}{|c|}{ INTERNAL-TIN Nb3Sn STRAND } \\
\hline Diameter [mm] & $0.821-0.822$ & $0.776-0.777$ \\
\hline Twist pitch [mm] & $13, \mathrm{RH}$ & $14, \mathrm{RH}$ \\
\hline Cr plating $[\mu \mathrm{m}]$ & $1.34-1.89$ & $1.34-2.02$ \\
\hline $\mathrm{Jc}(12 \mathrm{~T}, 4.2 \mathrm{~K})$ & $916-959$ & $914-942$ \\
\hline $\begin{array}{l}\mathrm{Qh}+/-3 \mathrm{~T} \text { cycle, } \\
4.2 \mathrm{~K}[\mathrm{~mJ} / \mathrm{cc} \mathrm{nCu}\end{array}$ & 315 & $327-347$ \\
\hline RRR & $103-129$ & $123-140$ \\
\hline $\mathrm{n}$ value $12 \mathrm{~T}, 4.2 \mathrm{~K}$ & $21-25$ & $20-28$ \\
\hline $\mathrm{Cu}: \mathrm{nCu}$ & 1.07 & 1.07 \\
\hline \multicolumn{3}{|c|}{ COPPER WIRE } \\
\hline Diameter [mm] & 0.820 & $0.772-0.774$ \\
\hline Cr plating $[\mu \mathrm{m}]$ & 1.2 & $1.2-1.94$ \\
\hline RRR & $>100$ & $>100$ \\
\hline \multicolumn{3}{|c|}{ JACKETED CONDUCTOR } \\
\hline Conductor dia. $[\mathrm{mm}]$ & $43.68-43.85$ & $43.73-43.93$ \\
\hline Jacket material & \multicolumn{2}{|c|}{ Modified 316LN } \\
\hline Cable wrap $[\mathrm{mm}]$ & \multicolumn{2}{|c|}{$51 \times 0.076,35 \%$ overlap, LH, $304 \mathrm{SS}$} \\
\hline Sub-cable wrap [mm] & \multicolumn{2}{|c|}{$12.7 \mathrm{x} \sim 0.05,50 \%$ open, LH, $304 \mathrm{SS}$} \\
\hline Coolant channel [mm] & \multicolumn{2}{|c|}{ Perforated tube 9 OD $\times 7$ ID, $30 \%$ open, $316 \mathrm{~L}$} \\
\hline No. of strand in cable & $900 \mathrm{SC} / 522 \mathrm{Cu}$ & $1080 \mathrm{SC} / 516 \mathrm{Cu}$ \\
\hline \multirow[t]{2}{*}{ Cable layout } & {$[(2 \mathrm{SC}+1 \mathrm{Cu}) \times 3 \times 5$} & {$[((6 \mathrm{SC}+1 \mathrm{Cu}) \times 6+\mathrm{CC} 1)$} \\
\hline & $\times 5+C()] \times 6+$ tube & $\times 5+\mathrm{CC} 2] \times 6+$ tube \\
\hline Stage 1 pitch $[\mathrm{mm}]$ & $44.45(2 \mathrm{SC}+1 \mathrm{Cu})$ & $25.4(6 \mathrm{SC}+1 \mathrm{Cu})$ \\
\hline Stage 2 pitch $[\mathrm{mm}]$ & $85.73($ x 3$)$ & $127(\times 6+$ Core 1$)$ \\
\hline Stage 3 pitch $[\mathrm{mm}]$ & $127(\times 5)$ & $254(\times 5+$ Core 2$)$ \\
\hline Stage 4 pitch $[\mathrm{mm}]$ & $254(\times 5+C C)$ & $457($ × 6$)$ \\
\hline $\mathrm{Cu}$ core (CC) pitches & $44.45 / 101.6(3 \times 4)$ & CC 1: $101.6(6+1)$ \\
\hline$[\mathrm{mm}]$ & & CC 2: 196.9 (x 3 CC1) \\
\hline Stage 5 pitch $[\mathrm{mm}]$ & $457.2(\times 6)$ & N/A \\
\hline
\end{tabular}

had a septuplet-based cabling pattern [5]. Similar cabling pattern with fewer strands and cabling stages was used to construct NHMFL 45 T hybrid magnet [6], [7].

The purposes of fabrication and test of the present sample are to compare the performances of conductors constructed with different cabling patterns, and to investigate the uniformity of current distribution in the present sample fabricated with sinter-bonded and solder-filled cable in the conductor termination. This paper focuses on the fabrication of the conductor sample [8]. The test results of TFUS1 are presented in a companion paper in these proceedings [9].

\section{SAMPLE CONDUCTORS}

Table I summarizes the construction of the as-built conductor sample legs [5]. Both baseline and alternate cables were made of internal-tin Nb3Sn strands with the same strand cross sectional construction. A smaller strand diameter was used in the alternate conductor in order to achieve the same target void fraction of $32.6 \%$ in the final cable.

Both conductors used a perforated stainless steel (SS) seam tube with a wall thickness of $1 \mathrm{~mm}$ and $30 \%$ opening as the central coolant channel. The conductor jacket was made of modi- 
fied $316 \mathrm{LN}$ seam tube with a wall thickness of $1.6 \mathrm{~mm}$. The same jacket material had been used to fabricate the CICCs in the NHMFL hybrid magnet [6]. Mechanical properties of the coldworked and aged base-metal and weld of the modified 316LN have been tested at $300 \mathrm{~K}$ and $4 \mathrm{~K}$ [10], which meet the ITER $\mathrm{TF}$ jacket requirements.

\section{SAMPLE DESIGN}

\section{A. Sample Termination}

The TFUS1 adopts termination used in the CS model coil inner module (CSMC-IM) [11], [12] modified to achieve uniformly low inter-strand resistivity. After removing the jacket, all cable wraps and $\mathrm{Cr}$ plating on all strands are removed before compaction. The cable in the termination is compacted inside a leak-tight braze assembled Glidcop/Monel tubular sleeve. $\mathrm{Cu}-\mathrm{Cu}$ sinter-bonds among neighboring strands and at the interface between the cable and the Glidcop sleeve are formed during reaction heat treatment. Furthermore, the sintered cable in the termination is solder-filled to increase interstrand contact area that benefits the uniformity of current distribution.

\section{B. Restrain of Cable Slippage}

The sample is designed to utilize the friction between the cable and the Glidcop sleeve in the compacted termination to restrain differential thermal contraction of the cable against the jacket in the straight conductor length during the cool-down phase in the reaction heat treatment. The terminations are compacted before heat treatment to a target void fraction of $20 \%$ and with a compacted length $>450 \mathrm{~mm}$. The compacted terminal sleeve is permanently welded to the conductor jacket before reaction. The friction between the cable and the sleeve is preserved in the post-reaction sample handling and cold test. Differential thermal strain should be constrained in the reacted sample leg. Crimping short section of CICC to a void fraction of $20 \%$ near the conductor-termination transition [4] is not used.

\section{Instrumentation}

The sample is instrumented with enhanced numbers of voltage taps and Cernox thermometers. Sensor positioned in the SULTAN high field zone is installed on a penetrating sensor mount, which will be described in a later section. The layout of the sensors along the conductor leg is detailed in [9].

\section{SAMPLE FABRICATION}

\section{A. Sample Leg}

1) Conductor Length: Each of the conductor leg was cut to a final length of $3460 \mathrm{~mm}$. The jacket and wrap were removed from each termination with a length of $520 \mathrm{~mm}$. The cable twist pitch was preserved with a number of SS band clamps.

2) Chrome Plating Removal From Termination: Removing chrome plating from all strands in the termination was achieved by dipping the cable in an $\mathrm{HCl}$ acid bath with a concentration of $18-20 \mathrm{w} \%$ [2]. All SS band clamps on the cable, except the one at free end, were removed. A $40 \mathrm{kHz}, 500 \mathrm{~W}$ ultrasonic transducer was used to agitate the bath for 30 minutes to promote chrome removal from strands buried deep inside the cable. The
TABLE II

SAMPLE Leg With Compacted TERMination

\begin{tabular}{lcccc}
\hline \multicolumn{3}{c}{ L2 } & & \\
\hline Sample leg & \multicolumn{2}{c}{ L3 } & \multicolumn{2}{c}{ Alternate } \\
\hline Total length, L2 [mm] & \multicolumn{2}{c}{ Baseline } & \multicolumn{2}{c}{3604} \\
CICC length, L3 [mm] & \multicolumn{2}{c}{3602} & 2296 \\
\hline Termination & BL lead & BL tail & ALT lead & ALT tail \\
\hline Monel-Jacket Overlap [mm] & 64 & 75 & 59 & 66 \\
Compacted Glidcop Dia., & $42.72 \pm$ & $42.72 \pm$ & $42.72 \pm$ & $42.72 \pm$ \\
D [mm] & 0.01 & 0.01 & 0.01 & 0.04 \\
Max Bend in Glidcop [mm] & 0.13 & 0.33 & 0.23 & 0.13 \\
\hline \hline
\end{tabular}

cable region was purged with nitrogen gas throughout the dipping process. After chrome removal, the cable was rinsed with distilled water and neutralized with saturated $\mathrm{NaHCO} 3$ solution. The copper surface was brightened with $50 \%$ diluted Kester 645 flux. This was followed by dipping the cable in water and methanol baths, and purging it with nitrogen gas till it dried. The SS band clamps were reinstalled on the dry cable after slightly tightening up the cable to recover the original pitch length. The end face of the chrome removed cable was TIG welded to prevent tin leakage during heat treatment.

3) Glidcop-Monel Sleeve: The terminal sleeve consisted of a Monel 400 cap, a Glidcop Al-15 tube with a wall thickness of $3 \mathrm{~mm}$, and a short length Monel 400 transition piece. The components were assembled and furnace brazed with $35 \mathrm{Au} 65 \mathrm{Cu}$ alloy in a reduction atmosphere. The brazed assembly was leak checked and inspected with radiography to assure that unbounded area does not cross the full width of the shear joint, and the overall unbounded area is less than $10 \%$ of the joint area.

4) Compaction of Conductor Termination: The accepted Glidcop-Monel sleeve was mounted over the chrome-removed cable in the termination. A hydraulic pointing machine with a compaction die of $42.8 \mathrm{~mm}$ dia. was used to form the termination. The void fraction in a compacted termination was estimated as $19 \%$. Table II shows the dimensions of the sample legs with compacted terminations. Less than $0.5 \%$ inconsistency in the length of the CICC was due to the discrepancy in the initial engagement of the cable end in the Glidcop tube. The bend of $<0.33 \mathrm{~mm}$ in the $\sim 470 \mathrm{~mm}$ long compacted termination was caused by the axial misalignment between the Glidcop tube and the Monel transition in the brazed assembly.

Intermittent welding process was used to join the Monel to the conductor jacket, which was pre-qualified to maintain the temperature of the cable under the weld joint below $200^{\circ} \mathrm{C}$. Alignment between the conductor and the termination was constantly measured and corrected during the welding process.

\section{B. Pointing Sensor Mount}

Figs. 1(a), 1(b) show the design and fabrication of the penetrating sensor mount. A SS tube $(6.4 \mathrm{~mm} \times 9.5 \mathrm{~mm})$ was fusion welded to a $16 \mathrm{~mm}$ OD $\times 1.4 \mathrm{~mm}$ thick SS washer that was prebent to a radius conforming to the jacket outer surface. The OF $\mathrm{Cu}$ core was torched brazed in the SS tube using $72 \mathrm{Ag} 28 \mathrm{Cu}$ alloy $\left(\mathrm{T}_{\mathrm{mp}}=780^{\circ} \mathrm{C}\right)$. The upper cylinder was machined to a plateau $\sim 2.6 \mathrm{~mm}$ above the washer and with a $1.6 \mathrm{~mm}$ deep flat bottom 


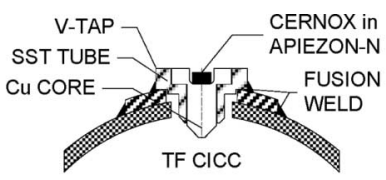

(a)

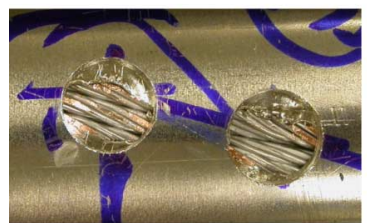

(c)
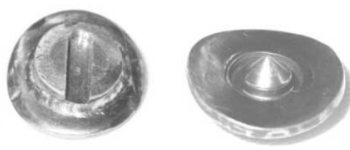

(b)

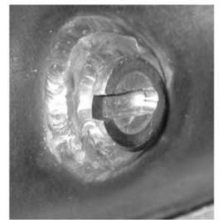

(d)

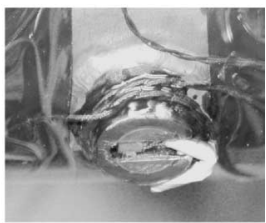

(e)
Fig. 1. (a) Design of the penetrating sensor mount with a $\mathrm{Cu}$ tip pointing $\sim 2$ $\mathrm{mm}$ into the cable; (b) top and bottom views of the penetrating sensor mount; (c) removing jacket and cable wraps at the sensor location; (d) welded sensor mount after heat treatment trial; (e) Cernox installed in the $\mathrm{Cu}$ groove with the lead wires thermally anchored around the mount.

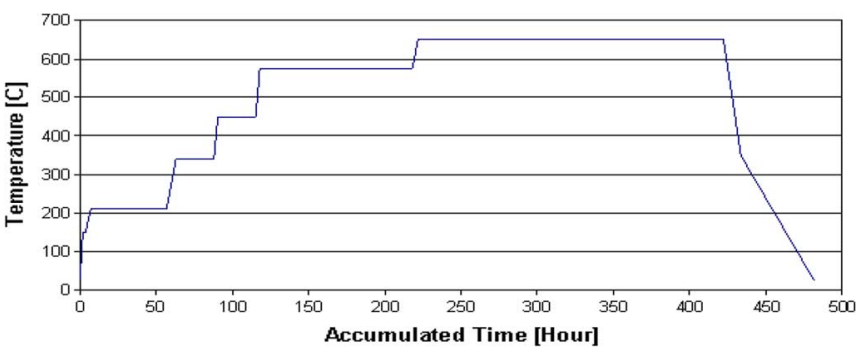

Fig. 2. Reaction heat treatment schedule for TFUS1 conductors.

groove across the diameter to house the Cernox-SD thermometer. The $\mathrm{Cu}$ core on the opposite side was machined into a pointing tip with a length penetrating into the cable region by $\sim 2 \mathrm{~mm}$.

At sensor location (Fig. 1(c)), the jacket was machined with a $6.4 \mathrm{~mm}$ dia. hole and the outer and sub-cable wraps were removed. No strand was broken during this process. Each sensor mount was installed with the $\mathrm{Cu}$ tip in contact with the strands in the cable. The washer flange was then fusion welded to the jacket before heat treatment (Fig. 1(d)). Again, intermittent weld was used to prevent overheating the cable.

\section{Reaction Heat Treatment}

The conductor legs were heat treated in a leak-tight retort purged with purified Ar gas. Each cable region was purged with an independent Ar circuit. The oxygen and water contents at the inlet of the purge gas were both below 0.05 PPM throughout the heat treatment. Four Jc barrels and one RRR samples were co-heat-treated with the conductors.

Fig. 2 shows the reaction heat treatment schedule defined by the strand manufacturer Luvata. The temperature distribution along the conductor length was within $\pm 5^{\circ} \mathrm{C}$ at any stage. The lag time of the load temperature during temperature ramping was less than 30 minutes at $\mathrm{T}<400^{\circ} \mathrm{C}$ and less than 15 minutes at $\mathrm{T}>400^{\circ} \mathrm{C}$.

\section{Solder Filling Sinter-Bonded Cable in the Termination}

All four terminations in the reacted TFUS1 sample legs were solder-filled. To allow coolant flowing through the termination, a $5.6 \mathrm{~mm}$ OD $\times 0.4 \mathrm{~mm}$ wall $\mathrm{Cu}$ tube was inserted inside the coolant channel before the process. In the terminations for making the joint, the upper end of the $\mathrm{Cu}$ tube was pre-brazed

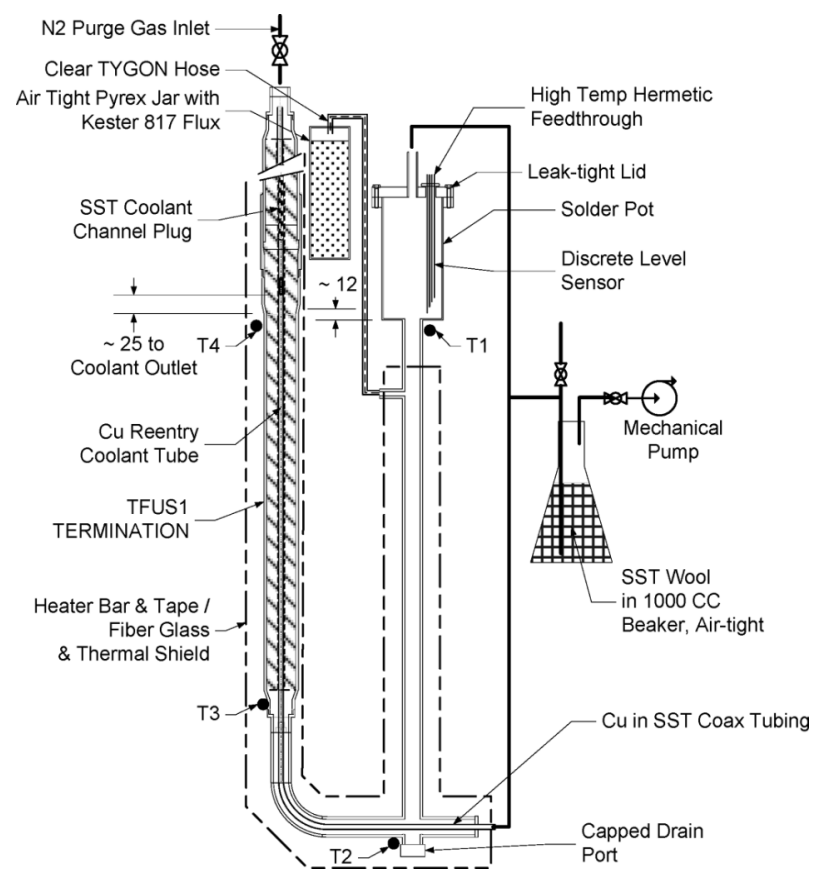

Fig. 3. Solder filling system and connections to sample termination.

with a $768 \mathrm{~mm}$ long SS rod that prevents the coolant from streaming through the central coolant channel in the high field zone [4]. Four $25 \mathrm{~mm} \mathrm{~L} \times 3.2 \mathrm{~mm} \mathrm{~W}$ openings were machined on the $\mathrm{Cu}$ tube near the braze joint, $\sim 13 \mathrm{~mm}$ above the neck of the compacted termination, as the coolant outlets to the conductor region. The $\mathrm{Cu}$ reentry tube was left in the central coolant channel after solder filling.

Both flux (Kester 817) and solder $(63 \mathrm{Sn} 37 \mathrm{~Pb})$ were fed into the cable region using gravity siphon [2], [7]. In order to remove gas trapped in the cavities in the sinter-bonded cable, the conductor and the system were evacuated during fluxing and solder-filling processes. Flux was introduced into the termination with the cable warmed up to $\sim 70^{\circ} \mathrm{C}$. The conductor was back-filled with $\mathrm{N} 2$ gas before rinsing out the flux with $1 \% \mathrm{HCl}$ solution and raising the termination temperature to $\sim 150^{\circ} \mathrm{C}$. The conductor was re-evacuated at a higher temperature.

As shown in Fig. 3, the bottom of a $22 \mathrm{~mm}$ dia. SS solder pot was welded with a $13 \mathrm{~mm}$ dia. SS feed tube that tapped into a coax tubing. The inner bottom of the solder pot was positioned at $\sim 12 \mathrm{~mm}$ below the neck of the compacted termination to prevent the molten solder from blocking the $\mathrm{Cu}$ reentry tube. The solder pot was sealed after loaded with solder alloy, evacuated and then heated with a propane torch when the temperatures in the termination and feed tube reached $250^{\circ} \mathrm{C}$. The discrete level sensor in the solder pot, made of isolated stainless steel rods of different lengths, was used to detect the melting of the solder alloy and measure the level of the molten solder.

The amount of solder filling in the termination was estimated from the difference in weights between the initial quantity and that left outside the termination after solder filling. As seen in Table III, 90\%-95\% of cable void space had been solder-filled.

At completion of the solder filling process, the coax feed tube was cut off from the termination. A final cap was welded to the termination after machining out the solder inside the brazed Monel cap between the open end and $\sim 6 \mathrm{~mm}$ above the weld line. 
TABLE III

Fraction of Solder Filled CABle Void SpaCe

\begin{tabular}{|l|c|c|c|c|}
\hline Termination & $\begin{array}{c}\text { Baseline } \\
\text { Upper }\end{array}$ & $\begin{array}{c}\text { Baseline } \\
\text { Lower }\end{array}$ & $\begin{array}{c}\text { Alt-A } \\
\text { Upper }\end{array}$ & $\begin{array}{c}\text { Alt-A } \\
\text { Lower }\end{array}$ \\
\hline Filling Fraction & $\sim 90 \%$ & $\sim 95 \%$ & N/A & $\sim 90 \%$ \\
\hline
\end{tabular}

\section{E. Sample Terminations and Joint}

A round bottom channel was machined to one side of a flat OF copper plate, which was soldered to the compacted Glidcop length to form the sample termination. The sample lower joint was assembled by soldering the conductor terminations to an OF copper bar pre-machined with mating grooves.

The bend in the compacted termination was sanded to below $0.13 \mathrm{~mm}$ in the soldering direction. The terminations and the $\mathrm{Cu}$ profiles were pre-tinned with $97 \mathrm{In} 3 \mathrm{Ag}$ alloy $\left(\mathrm{T}_{\mathrm{mp}}=143^{\circ} \mathrm{C}\right)$. Zinc chloride based soldering paste and solder foil $(0.25 \mathrm{~mm}$ thick) were used to solder the terminations and the joint. The soldering temperatures were both between $150^{\circ} \mathrm{C}$ and $165^{\circ} \mathrm{C}$. The averaged solder layer in the joint was estimated as $0.1 \mathrm{~mm}$ based on the weights of the solder alloy.

\section{F. Instrumentation}

All sensors positioned in the high field zone were installed after the lower joint was soldered. To accommodate $\sim 150$ diagnostic wires [9] in a design radial clearance of $0.85 \mathrm{~mm}$ between the conductor jacket and the clamp, Formvar coated 32 AWG lead wires were soldered directly to the jacket, the sensor mounts, and the Cernox thermometers.

As shown in Fig. 1(a), the voltage tap at the penetrating sensor mount was installed on the outer surface of the SS tube to avoid interference with mounting of the Cernox. The Cernox-SD was bonded to the bottom of the $\mathrm{Cu}$ groove with VGE-7031 varnish. Fig. 1(e) shows that the Cernox lead wires were coiled and expoxied around the penetrating sensor mount for thermal anchoring. Apiezon-N was used to improve thermal contact between the Cernox and the $\mathrm{Cu}$ surface. Kapton wedge and tape were then used to secure and insulate the sensors.

\section{G. Insulation and Clamping}

The conductor was insulated from the clamp with $0.25 \mathrm{~mm}$ thick G-10 sheath and $0.02 \mathrm{~mm}$ thick SS foil wrapping around the conductor to fill in the radial clearance to the clamp. Fig. 4(a) shows that the multilayer insulation was tailored into different lengths to cover the conductor surfaces between the adjacent sensors. Half of the lead wires were routed from the inboard to the outboard of the sample for connection to the diagnostic cable. Care was taken to assure that the radial build of the lead wire was less than the thickness of the insulation. After the conductor legs were secured with heavy SS clamps, twisted Teflon insulated wires were used to connect the lead wires to the electrical connectors [4]. The coolant tubing were welded to the top and bottom ends of each sample leg, and insulated with $0.1 \mathrm{~mm}$ thick Kapton tape. As seen in Fig. 4(b), plastic angles were installed along the corners of the clamps to insulate the sample from the facility test well. The finished sample was pressurized then leak checked to meet the requirements in [4].
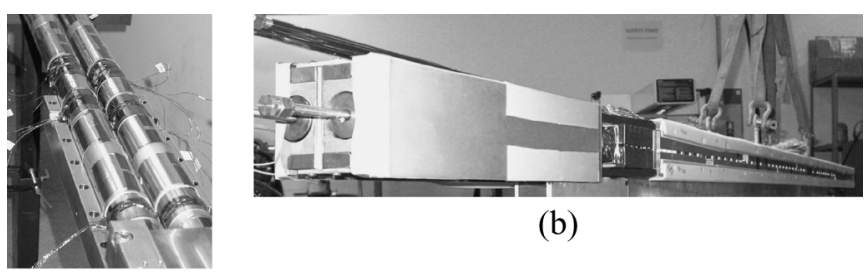

(b)

(a)

Fig. 4. (a) Conductor surfaces between adjacent sensors were electrical insulated from the conductor clamps with multilayer of G-10 sheaths and SS foils; (b) plastic angles were installed on the sample corners to insulate the clamps from the test well.

\section{SUMMARY}

The first US TF conductor sample constructed with two conductors using distinct cabling patterns, sinter-bonded then solder-filled terminations, and enhanced instrumentation has been successfully fabricated. The test results presented in a companion paper [9] indicate that the featured termination and joint built in the TFUS1 conductor sample could improve the quality of the short sample test results and benefit the qualification of the ITER conductors.

\section{ACKNOWLEDGMENT}

The authors thank Drs. P. Bruzzone and B. Stepanov at CRPP for their valuable advice and assistance on sample design and preparation, and SUPERCON Inc, MA for their kindly corporation in chrome removal process. C.Y. Gung thanks D. Tracey and MIT Alcator personnel for their excellent technical support during this sample fabrication.

\section{REFERENCES}

[1] N. Mitchell et al., "The ITER magnet system," IEEE Trans. Appl. Superconductivity, vol. 18, pp. 435-440, 2008.

[2] P. Bruzzone et al., "Results of a new generation of ITER TF conductor samples in SULTAN," IEEE Trans. Appl. Superconductivity, vol. 18, pp. 459-462, 2008.

[3] D. Bessette and N. Mitchell, "Review of the results of the ITER toroidal field conductor R\&D and qualification," IEEE Trans. Appl. Superconductivity, vol. 18, pp. 1109-1113, 2008.

[4] Specification of the Sultan Short Sample for the Qualification of the ITER Conductors revision V-03, Nov. 2006, unpublished.

[5] N. N. Martovetsky, TFUS1 TableR1.doc Jan. 12, 2008, unpublished.

[6] J. R. Miller, "The NHMFL 45-T hybrid magnet system: Past, present, and future," IEEE Trans. Appl. Superconductivity, vol. 13, pp. 1385-1390, 2003.

[7] T. A. Painter et al., "Progress in the manufacture of the cable-in-conduit Nb3Sn outsert coils for the 45 Tesla hybrid magnet," IEEE Trans. Magnetics, vol. 30, pp. 2204-2207, 1994.

[8] C. Y. Gung and J. H. Kim, TFUS1 Short Sample Fabrication Report MIT internal report, ITER-USMIT-GUNG-20080420-01, April 2008, unpublished.

[9] N. N. Martovetsky et al., "Test results of the first US ITER TF conductors in SULTAN," in , in these proceedings.

[10] J. H. Kim and J. Feng, "The 4 K mechanical properties of modified SS316LN for jacket materials in superconducting fusion magnets," Adv. Cryo. Eng. (Material), vol. 54, pp. 92-99, 2008.

[11] C. Y. Gung et al., "Design and manufacture of the US-ITER prepototype joint sample," IEEE Trans. Appl. Superconductivity, vol. 7, pp. 469-472, 1997

[12] R. Jayakumar et al., "Fabrication of ITER central solenoid model coil inner module," IEEE Trans. Appl. Superconductivity, vol. 7, pp. 981-984, 1997. 